\title{
Tacrolimus Therapeutic Drug Monitoring in Vietnamese Renal Transplant Recipients
}

\author{
Van Anh T. Nguyen ${ }^{1,4,6}$, Thang Viet Le ${ }^{2,6}$, Manh Van Bui ${ }^{3,6, *}$, Toan Quoc Pham ${ }^{2,6}$, Son The Trinh ${ }^{6}$, Binh Nhu Do ${ }^{5,6}$, \\ Lien Huong T. Nguyen ${ }^{4, *}$
}

Van Anh T. Nguyen ${ }^{1,4,6}$, Thang Viet Le $^{2,6}$, Manh Van Bui ${ }^{3,6, *}$, Toan Quoc Pham ${ }^{2,6}$, Son The Trinh ${ }^{6}$, Binh Nhu Do $^{5,6}$, Lien Huong T. Nguyen ${ }^{4, *}$

'Department of Pharmacy, Military Hospital 103, Ha Dong, Ha Noi 121-08, VIETNAM.

${ }^{2}$ Department of Renal and Haemodialysis, Military hospital 103, Ha Dong, Ha Noi 12108, VIETNAM.

${ }^{3}$ Center for Emergency Medicine, Intensive Care and Toxicology control, Military hospital 103, Ha Dong, Ha Noi 121-08, VIETNAM. ${ }^{4}$ Department of Clinical Pharmacy, Hanoi University of Pharmacy, 13-15 Le Thanh Tong, Hoan Kiem, Ha Noi 110-19, VIETNAM. ${ }^{5}$ Division of Military Science, Military Hospital 103, Ha Dong, Ha Noi 121-08, VIETNAM. ${ }^{6}$ Vietnam Military Medical University, $\mathrm{Ha}$ Dong, Ha Noi 121-08, VIETNAM.

\section{Correspondence}

\section{Lien Huong T. Nguyen}

Associate Professor, Department of Clinical Pharmacy, Hanoi University of Pharmacy, 13-15 Le Thanh Tong, Hoan Kiem, Ha Noi 110-19, VIETNAM.

E-mail: huongnt|@hup.edu.vn

\section{Manh Van Bui}

Associate Professor, Center for Emergency Medicine, Intensive Care and Toxicology control, Military Hospital 103, Ha Dong, Ha Noi 121-08, VIETNAM.

E-mail: drmanhbui@gmail.com

History

- Submission Date: 28-04-2020;

- Review completed: 25-05-2020;

- Accepted Date: 03-06-2020.

DOI : 10.5530/pj.2020.12.139

Article Available online

http://www.phcogj.com/v12/i5

Copyright

(C) 2020 Phcogj.Com. This is an openaccess article distributed under the terms of the Creative Commons Attribution 4.0 International license.

\section{ABSTRACT}

Background: Use of tacrolimus (Tac) is pivotal to renal transplant (RT) immunosuppressive maintenance regiments. The most frequently used means of Tac monitoring is the measurement of the trough concentration ( $\mathrm{C} 0$ ) in whole blood to maintain drug efficacy and minimize the consequences of overexposure. Most previous studies focused on therapeutic drug monitoring of Tac in renal transplant recipients and assessed the clinical response of patients. Our study aimed to describe a real Tacrolimus therapeutic drug monitoring transplantation and determine the clinical outcomes in Vietnamese adult renal transplant recipients. Methods: This retrospective study including 114 adult renal transplant patients (89 men and 25 women) with a mean age of $35.4 \pm 8.98$ years has been performed from August 2012 to March 2018 at Military Hospital 103 (Vietnam). Tac trough concentrations were adjusted according to the target range proposed by the European consensus conference on tacrolimus optimization. Samples for determination of tacrolimus blood levels were subdivided according to the posttransplantation period into three groups (0-3 months (G1), 3-12 months (G2) and over 1 year (G3). Median Years of follow-up was 15.4 months [range 0.233 to 68.4 months]. Results: A total of 3037 blood samples for the determination of tacrolimus trough concentration were obtained. Median concentrations were $6.7(4.5-10.2) \mathrm{ng} / \mathrm{ml}, 6.4(5.1-8.3)$ and $5.6(4.5$ to 7.1$) \mathrm{ng} / \mathrm{ml}$ for $\mathrm{G} 1, \mathrm{G} 2, \mathrm{G} 3$, respectively. After transplantation, three acute rejection (AR) events were documented (Cellular AR: 2, Humoral AR: 1). Cytomegalovirus, BK polyomavirus, Hepatitis $B$ virus and Hepatitis $C$ virus were detected in 7, 4, 7 and 3 renal post- transplant recipients, respectively. There were 5 patients with post-transplant diabetes (NODAT) and all of them had to convert to cyclosporine. 6 patients developed chronic kidney disease (CKD) after transplantation and 2 case with Tac-associated nephrotoxicity with proven biopsy. This observational study provided a real Tacrolimus therapeutic drug monitoring transplantation in Vietnamese renal transplant recipients. Main outcomes were acute rejection, post-transplant viral infections, neurotoxicity, NODAT, CKD, and Tac-associated nephrotoxicity.

Key words: Tacrolimus, Therapeutic drug monitoring, Renal transplantation, Vietnam.

\section{INTRODUCTION}

Tacrolimus (Tac) is a potent immunosuppressant drug that is well established for primary immunosuppression in kidney transplantation. It was introduced in the late 1980s as an alternative to cyclosporine-A for the prevention of graft rejection following solid organ transplantation. ${ }^{1}$ Due to a narrow therapeutic index and its large interpatient and intra-patient pharmacokinetic variability, therapeutic drug monitoring (TDM) is routinely performed for individualization of the Tac dose to maintain drug efficacy and minimize the consequences of overexposure. ${ }^{2}$ Nowadays, the most frequently used method of Tac monitoring is the measurement of the trough concentration (C0) in whole blood.

Therapeutic ranges of Tacrolimus have been changed remarkably. In 1995, Lake Louise Consensus Conference recommend preliminary target range of 5 to $20 \mathrm{ng} / \mathrm{mL}^{3}{ }^{3}$ Tacrolimus trough concentrations were targeted at 3-7 ng/mL with Symphony- Elite. ${ }^{4}$ Recently, the European experts on tacrolimus (2009) have proposed new target ranges of trough concentration based on both drug combination and post-transplantation delay. In regiment with mycophenolate mofetil (MMF) and steroid minimization, tacrolimus whole blood concentrations should range from 10 to $15 \mathrm{ng} / \mathrm{ml}$ during the first 3 months after transplantation, 8 - 12 $\mathrm{ng} / \mathrm{ml}$ in the next period ( 3 months -12 months), and from $5 \mathrm{ng} / \mathrm{ml}$ to $10 \mathrm{ng} / \mathrm{ml}$ thereafter. ${ }^{5}$

There were studies have evaluated the trough level tacrolimus according to time post-transplantation as well as efficacy and safety within those targets. ${ }^{4,6}$ To now, there have been no reports of such studies performed on Vietnamese kidney transplant recipients. Our study aimed to simple description real Tacrolimus therapeutic drug monitoring and determine the outcomes in Vietnamese adult de novo renal transplant recipients.

\section{MATERIALS AND METHODS}

A retrospective study was carried out at Department of Renal and Haemodialysis, Military Hospital 103, including one hundred and fourteen Vietnamese

Cite this article: Nguyen TVA, Le VT, Bui VM, Pham OT, Trinh TS, Do NB, et al. Tacrolimus Therapeutic Drug Monitoring in Vietnamese Renal Transplant Recipients. Pharmacogn J. 2020;12(5):984-92. 
patients undergoing renal transplantation. Data of patients were obtained between August 2012 and March 2018. Patients between the ages of 18 and 75 years who received the first single-organ renal transplant from either a living donor or a deceased donor were eligible. Exclusion criteria were paediatric kidney transplant recipients, retransplant or multi-organ transplant patients.

\section{Immunosuppressant protocol used}

The immunosuppressive protocol followed in our institution consisted of a triple drug regimen consisting of tacrolimus, mycophenolate mofetil (MMF) and steroids. Induction therapy included basiliximab (Simulect ${ }^{\circ}$, Novartis) pre- and 4 days postoperatively and $500 \mathrm{mg}$ intravenous (IV) methyl prednisolone (Solu Medrol ${ }^{\circledR}$ : Pfizer) pre and $12 \mathrm{~h}$ postoperatively. Oral tacrolimus (Prograf ${ }^{\oplus}$, Astellas Pharma) was started preoperatively with a dose of $0.1 \mathrm{mg} / \mathrm{kg} / \mathrm{day}$ administered in two divided doses. The doses were adjusted in the range therapy followed European consensus conference (2009) or occurrence of the event of adverse effects, rejection. Mycophenolate mofetil (Cellcept ${ }^{\oplus}$, Roche) was started with tacrolimus at a dose of $1 \mathrm{~g}$ twice a day and adjusted to lower doses in presence of diarrhea or infection. The next IV dose of steroid decreased by a half in consecutive days to $40 \mathrm{mg} /$ day within one to two weeks' post-transplant. Oral prednisolone $(15 \mathrm{mg} /$ day $)$ was initiated right after and was tapered every week to maintaining period of $5 \mathrm{mg} /$ day.

\section{Tacrolimus measurements}

Tac whole blood concentrations were determined using chemiluminscent microparticle immunoassay (CMIA, analysed on the Architect system, Abbott Diagnostics, IL, USA). The assay's detection limit was $0.8 \mathrm{ng} / \mathrm{ml}$.

Tac trough concentrations were collected prior to the morning dose. Frequency tacrolimus assays were three times weekly the first two weeks, once every week in the third week and fourth week and then at each patient visit during following months. Samples for determination of tacrolimus blood levels were subdivided according to the posttransplantation period into three groups: 0- 3 months (G1), 3-12 months (G2) and over 1 year (G3).

\section{Clinical outcomes}

Efficacy end points included renal function as indicated by the calculated eGFR during the study, acute rejection (AR), overall patient survival. The eGFR were calculated from serum creatinine measures with the use of the Modification of Diet in Renal Disease formula. ${ }^{7}$

Safety was evaluated by clinical assessment including vital signs and laboratory analyses designed to determine the incidence of adverse events. The common adverse events were neurotoxicity, new-onset diabetes (NODAT), post-transplant viral infections, and gastrointestinal disorders, chronic kidney disease and Tac-inducted nephrotoxicity.

NODAT was defined by the American Diabetes Association (ADA) diagnostic criteria ${ }^{8}$. Patients were diagnosed NODAT based plasma glucose criteria, either fasting plasma glucose $\geq 126 \mathrm{mg} / \mathrm{dL}(7.0$ $\mathrm{mmol} / \mathrm{L}$ ) or 2 -h plasma glucose $\geq 200 \mathrm{mg} / \mathrm{dL}(11.1 \mathrm{mmol} / \mathrm{L})$ during oral glucose tolerance test or $\mathrm{A} 1 \mathrm{C} \geq 6.5 \%$ or in a patient with classic symptoms of hyperglycemia crisis, a random plasma glucose $\geq 200 \mathrm{mg} /$ $\mathrm{dL}(11.1 \mathrm{mmol} / \mathrm{L})$.

The blood sample were obtained from recipients who were suspected to have $\mathrm{CMV}, \mathrm{BK}$ infection upon clinical presentation, physical examination and laboratory results. The disease was diagnosed according to the clinical features and quantitative polymerase chain reaction (qPCR) (and/or CMV antigenemia tests). Viral loads over
10000 copies/mL for BKV and over 1000 copies/mL for CMV were considered clinically relevant.

The diagnosis of chronic HBV infection was based upon the persistence of hepatitis B surface antigen (HBsAg) for more than 6 months after transplantation. The diagnosis of chronic HBV infection was made in a patient with a positive anti hepatitis $\mathrm{C}$ virus test (anti HCV) and positive molecular test that detects the presence of HCV RNA after transplantation.

Chronic kidney disease (CKD) was defined as being present if the glomerular filtration rate (GFR) was $<60 \mathrm{~mL} / \mathrm{min} / 1.73 \mathrm{~m}^{2}$ or evidence of kidney damage such as albuminuria or abnormal findings on renal imaging have been present for 3 months or more.

\section{Research ethics}

This study was approved by the Ethical Committee of Vietnam Military Medical University (No.169/2012/CN-HĐĐĐ issued on $20^{\text {th }}$ Jul 2012). The study was in line with the 1964 Declaration of Helsinki. The informed consent forms were signed by all participants after full explanation.

\section{Statistical analyses}

Data management and statistical analyses were carried out using RStudio sofware. Variable distribution was determined with the Shapiro-Wilk test. The Anova test was used to compare normally distributed variables, and the Mann-Whitney $U$ test was used to compare non-normally distributed variables. Variables with a normal distribution were expressed as the mean \pm standard deviation (SD) and those with an abnormal distribution were expressed as the median and their interquartile range (IQR). Differences in proportions were analyzed using Fisher's exact test. Time to all events, acute rejection (AR), cytomegalovirus (CMV) and chronic kidney disease (CKD) were analysed by the Kaplan-Meier method.

\section{RESULTS}

\section{Baseline characterstics of patients}

One hundred and fourteen patients (89 men and 25 women) undergoing renal transplantation were included from August 2012 to March 2018. The mean ( \pm SD) age was $35.4 \pm 8.98$ years. Median time of follow-up was 15.4 months [range 0.233 to 68.4 months]. Donors were mainly living people (97.4\%). The patients' general characteristics are presented in Table 1.

\section{The dosage of immunosuppressive drugs and Tac trough concentrations}

\section{Dosage of immunosuppressive drugs}

Tacrolimus doses in three groups are presented in Table 2. In our population, median tacrolimus doses were reduced after transplantation (0.1 tapered to $0.07 \mathrm{mg} / \mathrm{kg} /$ day). Daily dose of mycophenolate mofetil were $1.87 \pm 0.3 \mathrm{~g}$.

\section{Tacrolimus concentrations}

A total of 3037 blood samples for the determination of Tac concentrations were recorded. The mean number of samples per patient was 26.6 (range 4 to 60 ). Using a therapeutic range of European consensus conference (2009), 33.3\% tacrolimus concentrations were within target ranges in total and this proportion increased over time with the highest proportion in G3 (57\%) compared with those in G1 (22.3) and G2 (24.3\%). 2113 (48\%) trough concentrations were underthreshold with 886 (73.5\%), 570 (71.4\%) and 377 (36.5\%) in G1, G2 and G3, respectively (Figure 1). 
Table 1: Demographic and clinical characteristics of patients.

\begin{tabular}{lc}
\hline Variable & Value \\
\hline Age (years), mean (SD) & $35.4(8.98)$ \\
Male sex, n (\%) & $89(78)$ \\
BMI (kg/m²), mean (SD) & $20.0(3.26)$ \\
Time follow-up (median month), range & $15.4(0.2$ to 68.4$)$ \\
Hypertension, n (\%) & $106(93)$ \\
Virus, n (\%) & \\
HBV & $11(9.6)$ \\
HCV & $21(18.4)$ \\
HBV \& HCV & $3(2.6)$ \\
Induction therapy, n (\%) & $80(70.2)$ \\
Type of donor, n (\%) & \\
Deceased & $3(2.6)$ \\
Living related & $42(36.8)$ \\
Living unrelated & $69(60.5)$ \\
PRA, $n$ (\%) & \\
$\quad$ Negative & $86(75.4)$ \\
Positive PRA Class I & $14(12.3)$ \\
Positive PRA Class II & $8(7.0)$ \\
Positive HLA Class I \& II & $6(5.3)$ \\
HLA mismatches, n (\%) & \\
0 & $1(0.7)$ \\
1-3 & $50(43.9)$ \\
4-6 & $63(55.4)$ \\
Groups divided according post-transplant time & \\
Group 1 (G1) & $0-3$ months \\
Group 2 (G2) & $3-12$ months \\
Group 3 (G3) & $>12$ months \\
\hline
\end{tabular}

Note: BMI: Body mass index; HBV: Hepatitis B virus; HCV: Hepatitis C virus; PRA: panel-reactive antibodies; HLA: human leucocyte antigen;

Table 2: Concentrations and doses of three groups.

\begin{tabular}{ccccc}
\hline & G1 & G2 & G3 \\
$(\mathrm{n}=114)$ & $(\mathrm{n}=99)$ & P value & $<7)$ \\
\hline Dose $(\mathrm{mg} / \mathrm{kg} / \mathrm{day})^{\mathrm{a}}$ & $0.1(0.09-0.12)$ & $0.1(0.08-0.12)$ & $0.07(0.05-0.09)$ & $<0.001$ \\
$\mathrm{C} 0(\mathrm{ng} / \mathrm{ml})^{\mathrm{a}}$ & $6.7(4.5-10.2)$ & $6.4(5.1-8.3)$ & $5.6(4.5-7.1)$ & $<0.001$ \\
\hline
\end{tabular}

${ }^{a}$ Results are expressed as median (IQR)

\section{Clinical outcomes}

\section{Efficacy measurements}

Renal function: Overall, renal function was remained relatively stable from about 4 weeks postoperatively. The eGFR was the most highest in the second group (G2) [64.9 v.s $61.0(\mathrm{G} 1)$ and $62.7(\mathrm{G} 3)$; $\mathrm{P}<0,001]$ and then decreased following a year.

Acute rejection: Three biopsy-proven acute rejections (2.6\%) were reported during the study and all of them were in the first three months after transplantation (2 patients were cellular rejection and one case was humoral rejection). Base on Improving Global Outcomes (KDIGO) clinical practice guidelines, three AR patients were high-risk for rejection because of having one or more risk factors for acute rejection include more human leukocyte antigen (HLA) mismatches (2 patients with 6/6 mismatches), positive panel reactive antibody (PRA) Class II and delayed onset of graft function (1 patient).

Patient survival: Overall survival rates for patients were $98.2 \%$. Of the 2 deaths reported, 1 was caused by AR coexisting CMV pneumonia and the other was due to multi-organ CMV infection coexisting cerebral stroke and $\mathrm{HCV}$.
Safety: Serious adverse events were neurotoxicity, new-onset diabetes (NODAT), post-transplant viral infections, chronic kidney disease (CKD), Tac-associated nephrotoxicity and gastrointestinal disorders Table 3). While neurotoxicity and NODAT only occurred early in the study (G1), the others were found in later periods. Cumulative hazard of all events and some separated outcomes were estimated by KaplanMeier analysis (Figure 2).

Neurotoxicity were headache ( 2 case), insomnia (07 cases), nausea or vomit (1 case), tired and anorexia (2 case).

The incidence of post-transplant diabetes mellitus was $4.4 \%$ (5 patients) and all of them had to convert to cyclosporine.

Overall, incidence of post-transplant viral infections including CMV, $\mathrm{BKV}, \mathrm{HBV}$ and $\mathrm{HCV}$ were $6.1 \%, 3.5 \%, 6.1 \%$ and $2.6 \%$, respectively. In CMV patients, an organ disease was observed primarily (lungs $=5$; kidney $=1$ ) and 1 case of multi-organ infection. All four patients with BKV developed chronic kidney disease and two of these cases had to switch to cyclosporine. In addition to 4 patients with BKV, chronic kidney disease has been detected in two other cases.

Tac-associated nephrotoxicity was observed with proven biopsy in two patients. One patient with prolonged gastrointestinal disorders changed medication from Tac to cyclosporine. 


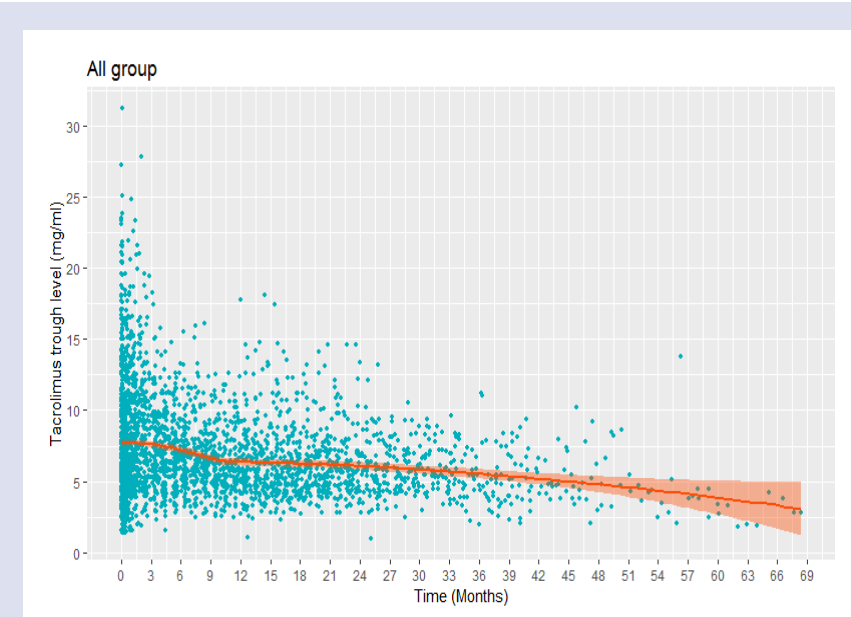

(a)

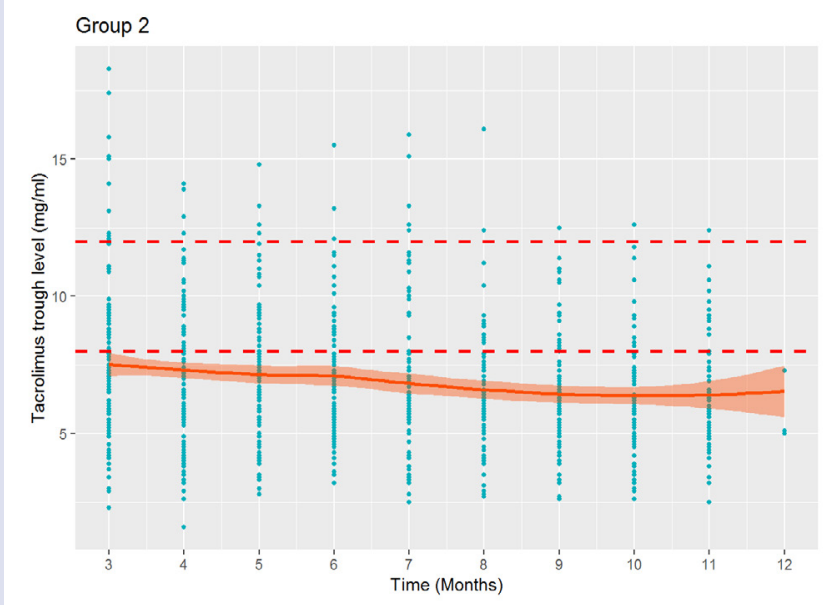

(c)

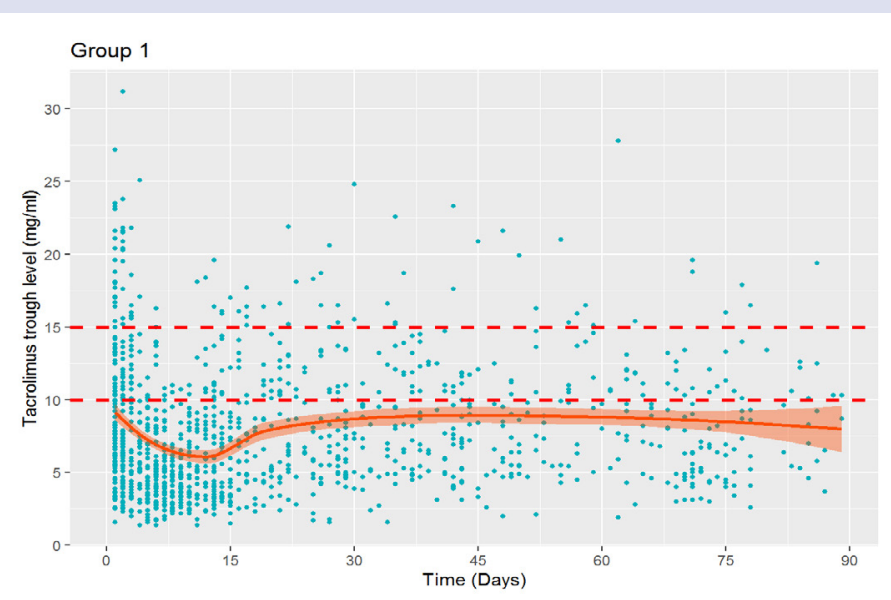

(b)

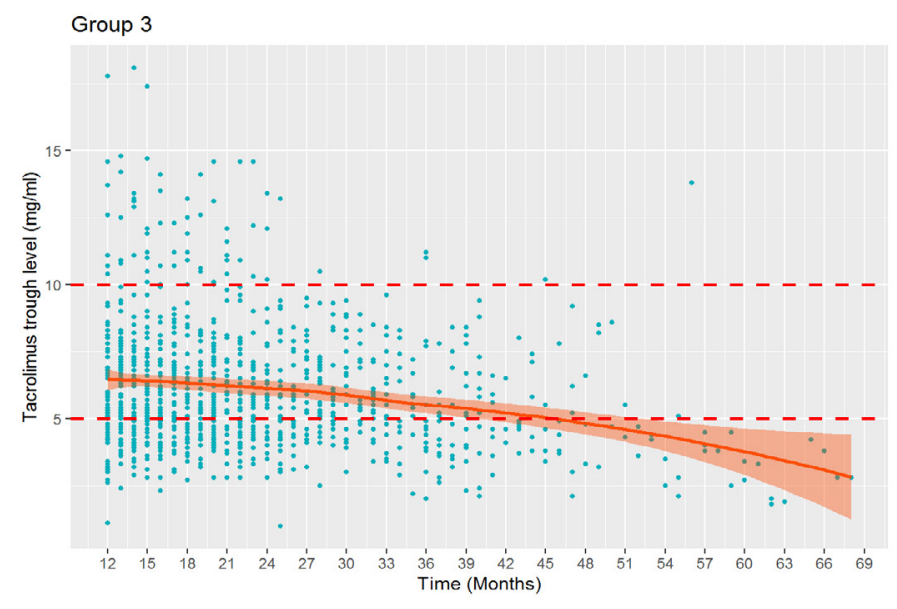

(d)

Figure 1: Tacrolimus concentrations after transplantation. (a), (b), (c), (d): Tac concentration in the study, group 1, group 2 and group 3, respectively. Dashed red lines represent the target range limit; solid red lines represent mean concentrations.

Table 3: Common clinical outcomes.

\begin{tabular}{ccccc}
\hline Outcomes & G1 & G2 & G3 & 0 \\
\hline Acute rejection & 3 & 0 & 4 & 0.18 \\
CMV & 0 & 4 & 3 & 0.02 \\
BKV & 0 & 1 & 3 & 0.046 \\
HBV & 0 & 4 & 1 & 0.34 \\
HCV & 0 & 2 & 3 & 0.04 \\
CKD & 0 & 3 & 0 & 0.03 \\
NODAT & 5 & 0 & & 0.04 \\
\hline
\end{tabular}

Note: New-onset diabetes (NODAT), chronic kidney disease (CKD). 


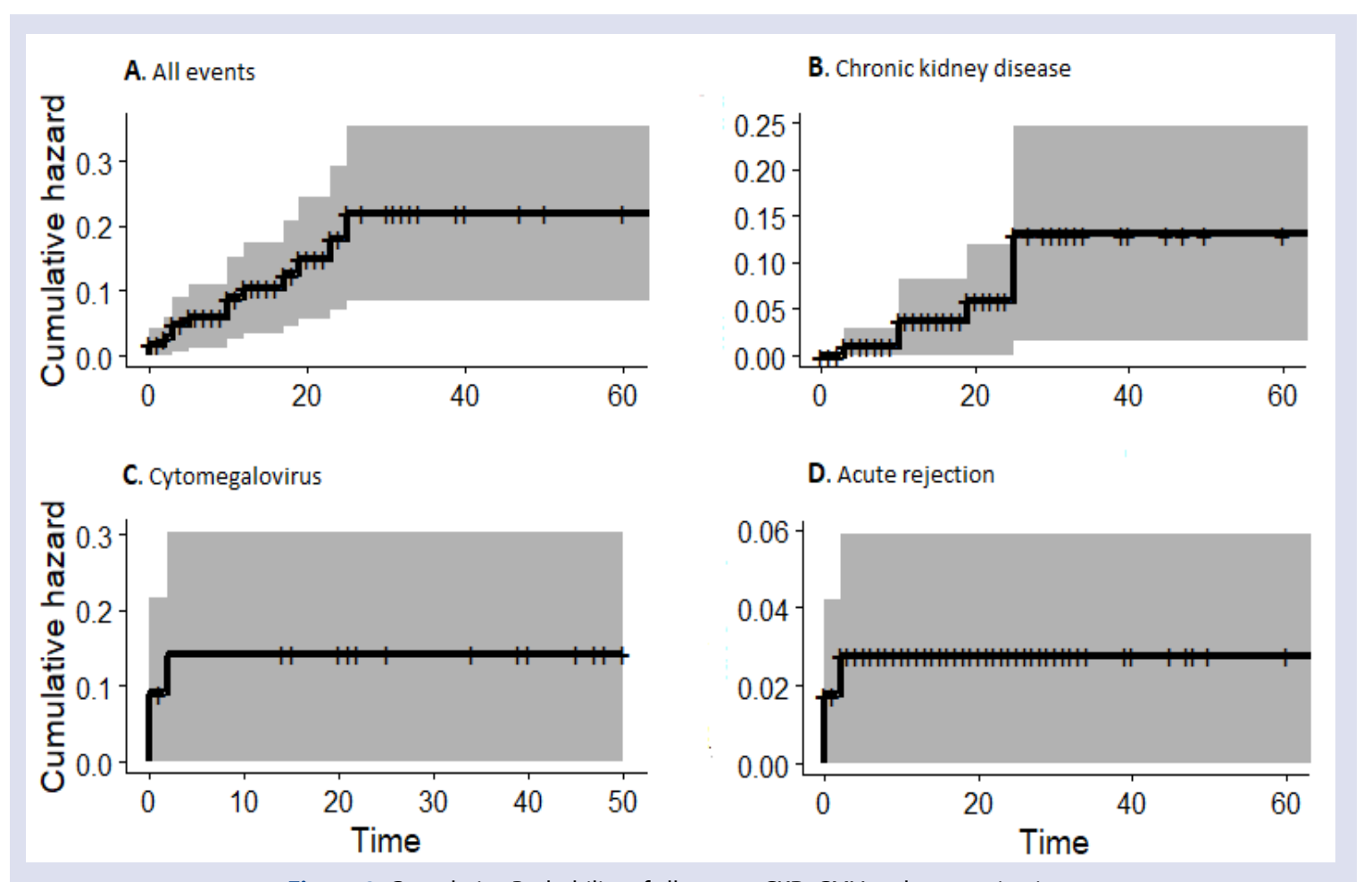

Figure 2: Cumulative Probability of all events, CKD, CMV and acute rejection.

\section{DISCUSSION}

Monitoring blood tacrolimus concentrations is considered necessary in maintaining drug efficacy and minimize the consequences of overexposure. ${ }^{5}$ Most previous studies focused on therapeutic drug monitoring of tacrolimus in renal transplant recipients and assessed the clinical response of patients. ${ }^{9110}$ However, only few studies have evaluated the trough tacrolimus according to time post-transplantation as well as efficacy and safety within those targets. ${ }^{4,6}$ The primary objective of our study was to summary simply the trough of tacrolimus according to post-transplantation period, as defined by the last European consensus conference (2009) and determine the outcomes in Vietnamese adult renal transplant recipients.

Our results showed that only $33.3 \%$ tacrolimus concentrations were within target ranges and $48 \%$ of trough blood levels were underthreshold. These results are agreeable with previous observation in Tunisian kidney transplant recipients had similar result. ${ }^{11}$ More than $50 \%$ of patients were outside the target range. The major reason is presumably the great inter-individual and intra-individual variation of drug levels. ${ }^{12}$ However, in some cases it could be attributed directed to an adverse event or to lack of efficacy once a patient has experienced acute rejection. These findings re-emphasized necessity of therapeutic drug monitoring (TDM) in renal transplant recipients.

In our population, the median daily dose was $0.1(0.09-0.12) \mathrm{mg} / \mathrm{kg}$ in first 3 months after transplantation and this dose reduced by time after transplantation. Some previous had also similar results. In a study performed on a American population, Narayanan et al..$^{10}$ showed that the dose in the first month, month 6 and 12 after transplantation were $0.13,0.1$ and $0.09 \mathrm{mg} / \mathrm{kg} /$ day, respectively. Takeuchi et al ${ }^{13}$ in study on a Japanese population had dose at $41.4 \pm 21.4$ day after transplantation $0.09 \pm 0.05 \mathrm{mg} / \mathrm{kg} /$ day. However, in Sugioka' study, the tacrolimus doses were higher during the first 3 months after transplantation (between 0.15 and $0.30 \mathrm{mg} / \mathrm{kg} /$ day). These differences in dosing requirement may be due to an interethnic polymorphism in the expression of tacrolimus metabolizing enzymes, i.e. cytochrome CYP3A5 and CYP3A4. It has been consistently demonstrated that CYP3A5 expressers (CYP3A $5{ }^{\star} 1$ carriers) had a lower dose-adjusted $\mathrm{C} 0$ and higher clearance, thus requiring higher tacrolimus doses in order to reach the same steadystate $\mathrm{C} 0$ when compared with CYP3A5 non-expressers (CYP3A $5^{\star} 3{ }^{*} 3$ carriers). Some studies found that expressers require approximately double the starting dose of tacrolimus. ${ }^{14},{ }^{15}$ Moreover, De Jonge et al. point out $\mathrm{P} 450$ oxydo-reductase $(\mathrm{POR})^{\star} 28 \mathrm{SNP}$ was associated with additional increases in early tacrolimus dose-requirements in patients carrying a CYP $3 \mathrm{~A} 55^{\star} 1$ allele. ${ }^{16}$ Besides, Elens et al. found that CYP $3 \mathrm{~A} 4{ }^{\star} 22$ was associated with a risk of supra-therapeutic Tac concentrations ( $>15$ $\mu \mathrm{g} / \mathrm{l})$ during the first 3 days after transplantation. ${ }^{17}$

The incidence of acute rejection was $2.6 \%$. Our proportion are low and similar or lower than those in other reports with a similar followup. ${ }^{18,19}$ Over the last two decades, there have been dramatic reductions in the incidence of AR related to the introduction of more effective immunosuppressive medications (such as mycophenolate mofetil), robust induction regimes and desensitization.

Development of NODAT has been associated with Tac exposure. ${ }^{20}$ NODAT increases the risk of cardiovascular events, graft failure and mortality. ${ }^{21}$ In our study, $4.4 \%$ developed NODAT within three months after transplantation. This low frequency is comparable to those in the Symphony study (10.6\% in the first year) and Kamar'study.,22 These percentages may roughly be compared since most cases of NODAT often occurs in the first 3 post-transplantation months. ${ }^{23}$ Risk factors for new-onset diabetes mellitus after kidney transplantation may make a difference in proportion of NODAT. Our patients were younger (35.4 \pm 8.98 vs. $45.4 \pm 14.7$ and $46.4 \pm 13.59$ years $)$, lower BMI $(20.0 \pm 3.26$ vs. $\left.23.4 \pm 3.95 \mathrm{~kg} / \mathrm{m}^{2}\right)$, lower proportion of $\mathrm{HCV}$ infection $(2.6 \%$ vs. $3.7 \%)$, different ethnicity and lower Tac concentrations in the first three months $(6.7(4.5-10.2) v s .>7$ and $10 \mathrm{ng} / \mathrm{ml})$.

In our study, the incidence of opportunistic infections including CMV, $\mathrm{BKV}, \mathrm{HBV}$ and HCV were low and similar or lower than those in other reports. ${ }^{24-27}$ We hypothesized that low proportion of post-transplant infections may be partly due to our lower Tac levels and careful pretransplant screening, immunization, and post-transplant prophylactic 
antimicrobials. These preparation may reduce the risk for posttransplant infection. ${ }^{28}$

\section{CONCLUSION}

This observational study provided a realistic Tacrolimus therapeutic drug monitoring transplantation in Vietnamese renal transplant recipients. Main clinical outcomes were acute rejection, post-transplant viral infections, neurotoxicity, NODAT, CKD and Tac-associated nephrotoxicity.

\section{ACKNOWLEDGMENTS}

In this study, we had been strongly supported by clinical application funding of our local hospital and university to complete our research.

\section{AUTHOR'S CONTRIBUTIONS}

Study design: Van Anh T. Nguyen, Lien Huong T. Nguyen, Thang Viet Le, Manh Van Bui

Data collection: Van Anh T. Nguyen, Toan Quoc Pham

Statistical analysis: Van Anh T.Nguyen, Lien Huong T. Nguyen

Data interpretation: Lien Huong T. Nguyen, Thang Viet Le, Manh Van Bui

Manuscript Preparation and Editing: Van Anh T. Nguyen, Lien Huong T. Nguyen, Thang Viet Le, Binh Nhu Do

Literature search: Van Anh T. Nguyen, Binh Nhu Do, Son The Trinh

Funds collection: Thang Viet Le, Manh Van Bui, Toan Quoc Pham, Son The Trinh

\section{CONFLICTS OF INTEREST}

The authors declare no conflict of interest, financial or otherwise.

\section{REFERENCES}

1. KDIGO clinical practice guideline for the care of kidney transplant recipients. Am J Transplant. 2009;9(3):S1-155.

2. De Jonge $H$, Naesens $M$, Kuypers DR. New insights into the pharmacokinetics and pharmacodynamics of the calcineurin inhibitors and mycophenolic acid: possible consequences for therapeutic drug monitoring in solid organ transplantation. Ther Drug Monit. 2009;31(4):416-35.

3. Jusko WJ, Thomson AW, Fung J. Consensus document: therapeutic monitoring of tacrolimus (FK-506). Ther Drug Monit. 1995;17(6):606-14.

4. Ekberg $H$, Tedesco-Silva $H$, Demirbas A. Reduced exposure to calcineurin inhibitors in renal transplantation. N Engl J Med. 2007;357(25):2562-75.

5. Wallemacq P, Armstrong VW, Brunet M. Opportunities to optimize tacrolimus therapy in solid organ transplantation: report of the European consensus conference. Ther Drug Monit. 2009;31(2):139-52.

6. Storset E, Asberg A, Hartmann A. Low-target tacrolimus in de novo standard risk renal transplant recipients: A single-centre experience. Nephrology. 2016;21(10):821-7.

7. Levey AS, Bosch JP, Lewis JB, Greene T, Rogers N, Roth D. A more accurate method to estimate glomerular filtration rate from serum creatinine: a new prediction equation. Modification of Diet in Renal Disease Study Group. Annals of internal medicine. 1999;130(6):461-70.
8. 2. Classification and Diagnosis of Diabetes: Standards of Medical Care in Diabetes-2018. Diabetes care. 2018;41(Suppl 1):S13-27.

9. O'Seaghdha CM, McQuillan R, Moran AM. Higher tacrolimus trough levels on days 2-5 post-renal transplant are associated with reduced rates of acute rejection. Clin Transplant. 2009;23(4):462-8.

10. 1 Narayanan M, Pankewycz O, El-Ghoroury M. Outcomes in African American kidney transplant patients receiving tacrolimus and mycophenolic acid immunosuppression. Transplantation. 2013;95(4):566-72.

11. 1Ben Fredj N, Chaabane A, Chadly Z. Tacrolimus therapeutic drug monitoring in Tunisian renal transplant recipients: effect of post-transplantation period. Transpl Immunol. 2013;28(4):198-202.

12. 1 Ekberg H, Mamelok RD, Pearson TC, Vincenti F, Tedesco-Silva H, Daloze P. The challenge of achieving target drug concentrations in clinical trials: experience from the Symphony study. Transplantation. 2009;87(9):1360-6.

13. 1Takeuchi $H$, Matsuno $N$, Hirano T. Evidence of different pharmacokinetics between cyclosporine and tacrolimus in renal transplant recipients: why cyclosporine is monitored by $\mathrm{C} 2$ level and tacrolimus by trough level. Transplant Proc. 2008;40(7):2240-2.

14. 1Nair SS, Sarasamma S, Gracious N, George J, Anish TS, Radhakrishnan R Polymorphism of the CYP3A5 gene and its effect on tacrolimus blood level. Exp Clin Transplant. 2015;13 Suppl 1:197-200.

15. 1Tada H, Tsuchiya N, Satoh S. Impact of CYP3A5 and MDR1(ABCB1) C3435T polymorphisms on the pharmacokinetics of tacrolimus in renal transplant recipients. Transplant Proc. 2005;37(4):1730-2.

16. 1De Jonge $H$, Metalidis $C$, Naesens $M$, Lambrechts $D$, Kuypers DR. The P450 oxidoreductase *28 SNP is associated with low initial tacrolimus exposure and increased dose requirements in CYP3A5-expressing renal recipients. Pharmacogenomics. 2011;12(9):1281-91.

17. 1Elens $L$, Bouamar $R$, Hesselink DA. A new functional CYP3A4 intron 6 polymorphism significantly affects tacrolimus pharmacokinetics in kidney transplant recipients. Clin Chem. 2011;57(11):1574-83.

18. 1EITers M, Grande JP, Keddis MT. Kidney allograft survival after acute rejection, the value of follow-up biopsies. Am J Transplant. 2013;13(9):2334-41.

19. 1 Nankivell BJ, P'Ng CH, O'Connell PJ, Chapman JR. Calcineurin Inhibitor Nephrotoxicity Through the Lens of Longitudinal Histology: Comparison of Cyclosporine and Tacrolimus Eras. Transplantation. 2016;100(8):1723-31.

20. 2Yates CJ, Fourlanos S, Hjelmesaeth J, Colman PG, Cohney SJ. New-onset diabetes after kidney transplantation-changes and challenges. Am J Transplant. 2012;12(4):820-8

21. 2Guitard J, Rostaing L, Kamar N. New-onset diabetes and nephropathy after renal transplantation. Contrib Nephrol. 2011;170:247-25.

22. 2Kamar N, Mariat C, Delahousse M. Diabetes mellitus after kidney transplantation: a French multicentre observational study. Nephrol Dial Transplant. 2007;22(7):1986-93.

23. 2Montori VM, Basu A, Erwin PJ, Velosa JA, Gabriel SE, Kudva YC. Posttransplantation diabetes: a systematic review of the literature. Diabetes care. 2002;25(3):583-92.

24. 2Kliem V, Burg M, Haller $H$. Relationship of hepatitis B or C virus prevalences, risk factors, and outcomes in renal transplant recipients: analysis of German data. Transplant Proc. 2008;40(4):909-14

25. 2Scott DR, Wong JK, SpicerTS. Adverse impact of hepatitis $C$ virus infection on renal replacement therapy and renal transplant patients in Australia and New Zealand. Transplantation. 2010;90(11):1165-71.

26. 2Silva HT, Jr., Felipe CR, Garcia VD. Planned randomized conversion from tacrolimus to sirolimus-based immunosuppressive regimen in de novo kidney transplant recipients. Am J Transplant. 2013;13(12):3155-63.

27. 2 Huang G, Zhang L, Liang X. Risk factors for BK virus infection and BK virusassociated nephropathy under the impact of intensive monitoring and preemptive immunosuppression reduction. Transplant Proc. 2014;46(10):3448-54.

28. 2Karuthu S, Blumberg EA. Common infections in kidney transplant recipients. Clin J Am Soc Nephrol. 2012;7(12):2058-70. 


\section{GRAPHICAL ABSTRACT}

\section{Tacrolimus therapeutic drug monitoring in renal transplant recipients}

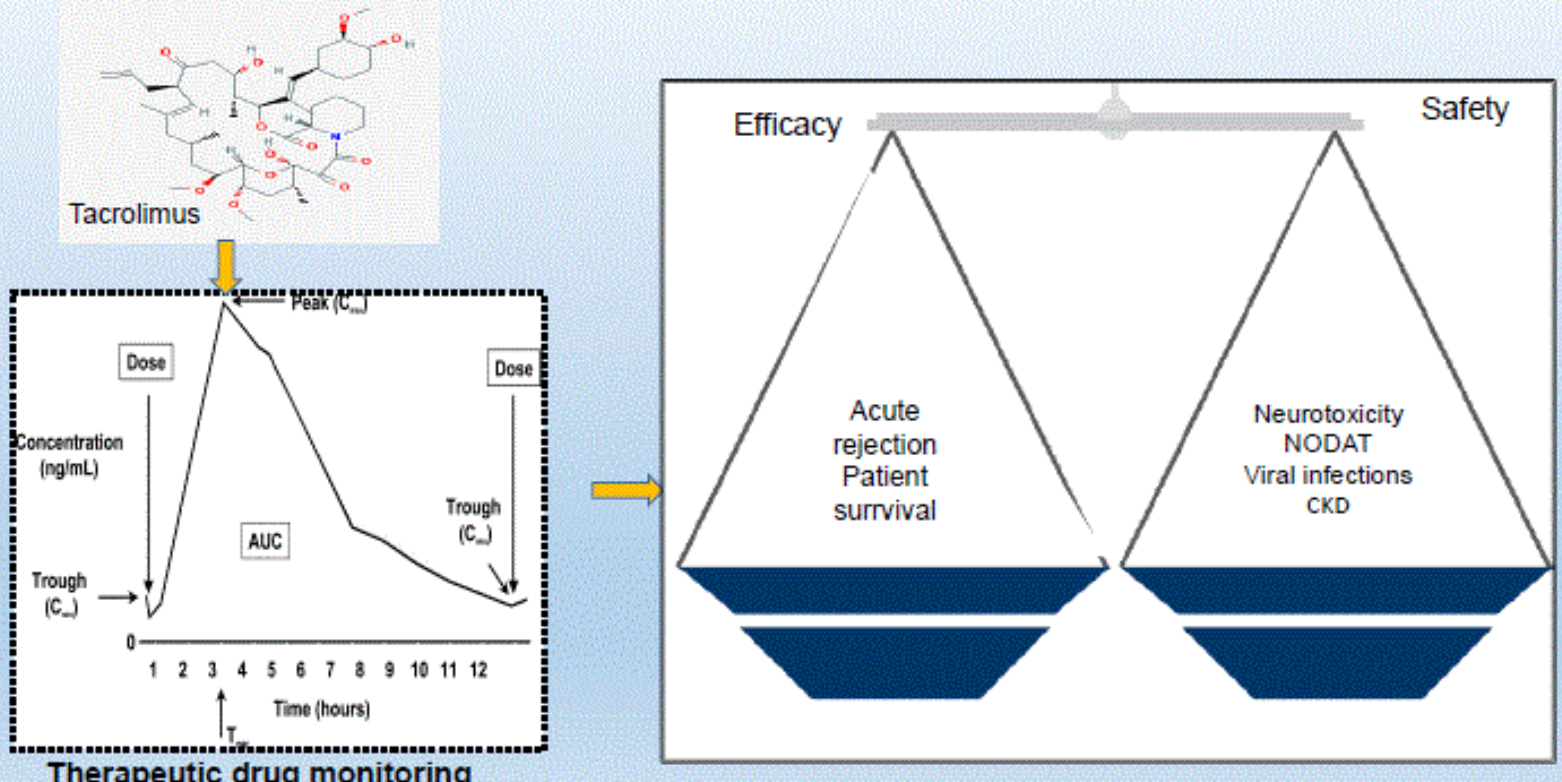

\section{ABOUT AUTHORS}

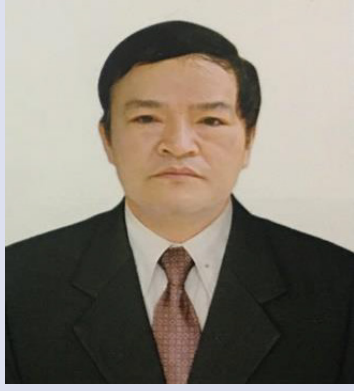

\section{Fullname: Manh Van Bui}

He was born in Thai Binh, Vietnam, in 1962.

He graduated general doctor in from the Vietnam Military Medical University (VMMU), Hanoi, Vietnam, in 1989.

He finished the Ph.D in Medicine, from the Vietnam Military Medical University, Hanoi, in 2009. In 1989, he joined the Intensive Care Unite, Military Hospital 103 as Attending Phycician and as a Lecture since 2004 in Centre of Emergency, Intensive Care Medicine and Clinical Toxicology, VMMU, where he has been an Associated Professor in 2015.

His current research interests include Intensive Care, Nephrology and Organ Transplantation.

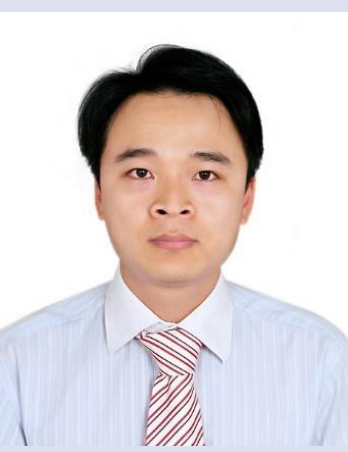

\section{Full name: Binh Nhu Do}

Sex: Male

Date of birth: Nov.1983

Location of birth: Ha Noi, Viet Nam

Email: nhubinh.do@vmmu.edu.vn

Graduated at Vietnam Military Medical University: Genaral Practitioner - 2008; PhD in 2018

Current work: Department of Infectious Disease, Vietnam Military Medical University.

Division of Military Science, Military Hospital 103, Ha Noi, Vietnam

The main research fields: My principal research of interest lies in the field of Infectious Diseases. I am currently investigating the impact of bacteria, viruses, parasites pathogens on human's health and using traditional and modern techniques to diagnose the diseases caused by bacteria, viruses, parasites and others. 


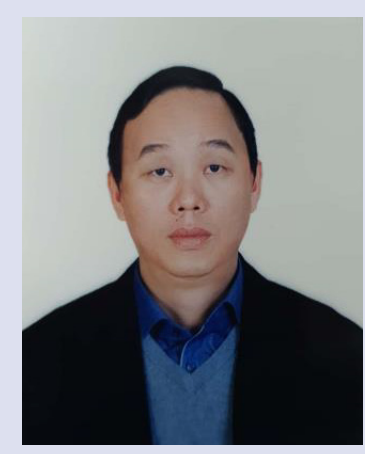

\section{Name: Son The Trinh}

Date of birth: August 15, 1973

Gender: Male

Nationality: Vietnamese

Email: trinhtheson@vmmu.edu.vn

Current position: Associate Prof; Vice Director of Military Institute of Clinical Embryology and Histology, Vietnam Military Medical University (VMMU)

Address: Military Institute of Clinical Embryology and Histology, Vietnam Military Medical University (VMMU), 222 Phung Hung road, Ha Dong district, Ha Noi, Vietnam

\section{Awards:}

- The Second Prize of The Vietnam Science and Technology Initiative Award 1999.

- The Badge of Creative Youth and the First Prize of The 12th Vietnam Scientific \& Technological Competition among Medical and Pharmaceutical Universities

- The third prizes of Vietnam Fund for Supporting Technological Creations (VIFOTEC), 2012

- The Silver price of Seoul International Invention Fair 2013, organized by Korea Invention Promotion Association in Seoul, Korea.

- Patent No 12568, National Office of Intellectual Property of Vietnam

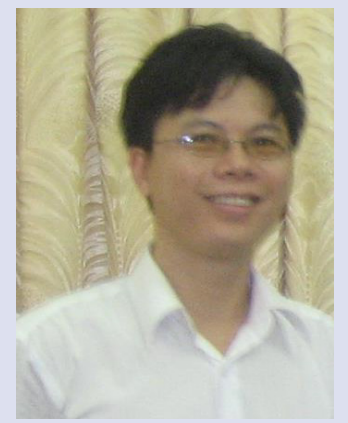

\section{Asso. Prof. Thang Viet Le, MD. PhD}

Sex: Male

Date of birth: 24th November 1969

Nephrologist

Department of Nephrology and Hemodialysis

Military Hospital 103

N0 261, Phung Hung Street, Ha Dong District, Ha Noi Capital, Viet Nam

Graduation of Medical Doctor Training in Vietnam Military Medicine University (1087-1993)

Graduation of PhD' Course in Nagasaki Medicine University (2002-2006)

Become Associate Professor in Kidney, Dialysis Field in 2012.

Co-Author of one chapter book in English (2005)

Editor in Chief of 02 Vietnamese books

Articles Published in 128 Vietnamese papers and 13 English papers (All are the first and corresponding author).

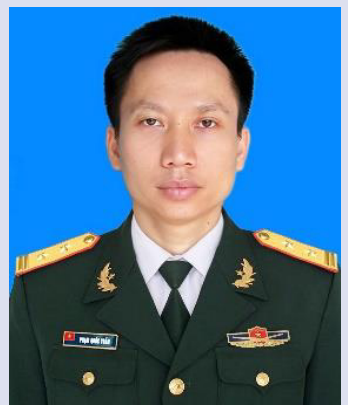

\section{Full name: Toan Quoc Pham}

Sex: Male

Date of birth: 15.11.1977

Location of birth: Nam Dinh province, Viet Nam

Graduated at Vietnam Military Medical University: Genaral doctor - 2002

Graduated Medical Doctor in nephrology at Vietnam Military Medical University: 2015

Recognized title of Associate Professor: 2019

Current work: Vise Head of Nephrology and Hemodialysis Department, 103 Hospital, practical hospital of Vietnam Military Medical University.

The main research fields: diabetic nephropathy, kidney failure, kidney transplant

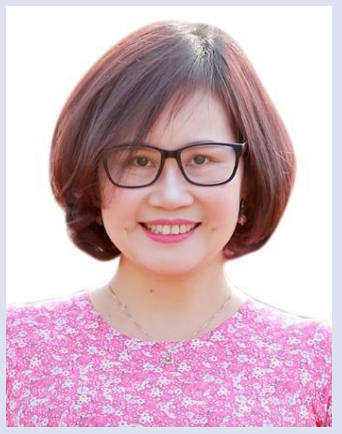

\section{Full name: Lien Huong T. Nguyen}

She was born in Hanoi, Vietnam, in 1974.

She graduated in 1996 at Hanoi University of Pharmacy and received master's and doctoral degrees in clinical pharmacy from Hanoi University of Pharmacy in 1999 and 2010, respectively. She received the title of Associate Professor in 2016.

Nguyen Thi Lien Huong is currently the Head of Clinical Pharmacy Department, Hanoi University of Pharmacy and the Vice President of Hanoi Hospital Pharmacists Association. Her main research fields include Drug Use Evaluation, Clinical Pharmacokinetic, and Pharmaceutical Care. 


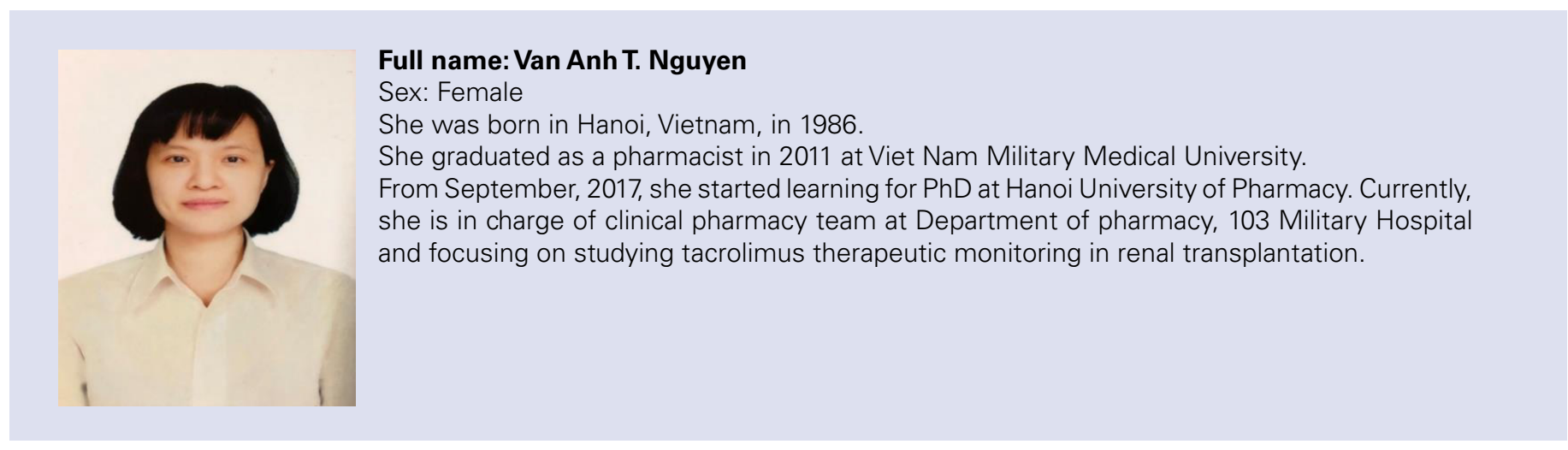

Cite this article: Nguyen TVA, Le VT, Bui VM, Pham QT, TrinhTS, Do NB, et al. Tacrolimus Therapeutic Drug Monitoring in Vietnamese Renal Transplant Recipients. Pharmacogn J. 2020;12(5):984-92. 